\title{
Musculoskeletal pain distribution in 1,000 Danish schoolchildren aged 8-16 years
}

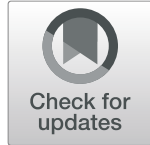

Signe Fuglkjær ${ }^{1 *}$ D, Werner Vach ${ }^{2,3}$, Jan Hartvigsen ${ }^{1,4}$, Kristina Boe Dissing ${ }^{1}$, Tina Junge ${ }^{1,5}$ and Lise Hestbæk ${ }^{1,4}$

\begin{abstract}
Background: Knowledge about the occurrence and distribution of musculoskeletal problems in early life is needed. The objectives were to group children aged 8 to 16 according to their distribution of pain in the spine, lower- and upper extremity, determine the proportion of children in each subgroup, and describe these in relation to sex, age, number- and length of episodes with pain.

Method: Data on musculoskeletal pain from about 1,000 Danish schoolchildren was collected over 3 school years (2011 to 2014) using weekly mobile phone text message responses from parents, indicating whether their child had pain in the spine, lower extremity and/or upper extremity. Result are presented for each school year individually.

Results: When pain was defined as at least 1 week with pain during a school year, Danish schoolchildren could be divided into three almost equally large groups for all three school years: Around 30\% reporting no pain, around $40 \%$ reporting pain in one region, and around $30 \%$ reporting pain in two or three regions. Most commonly children experienced pain from the lower extremities ( 60\%), followed by the spine ( 30\%) and the upper extremities $(\sim 23 \%)$. Twice as many girls reported pain in all three sites compared to boys (10\% vs. 5\%) with no other statistically significant sex or age differences observed. When pain was defined as at least 3 weeks with pain during a schoolyear, $40 \%$ reported pain with similar patterns to those for the more lenient pain definition of 1 week.
\end{abstract}

Conclusion: Danish schoolchildren often experienced pain at more than one pain site during a schoolyear, and a significantly larger proportion of girls than boys reported pain in all three regions. This could indicate that, at least in some instances, the musculoskeletal system should be regarded as one entity, both for clinical and research purposes.

Keywords: Paediatrics, Multi region pain, Children, Prevalence, Occurrence, Adolescence, Distribution

\section{Background}

Musculoskeletal (MSK) pain can start early in life [1-3] and increases throughout adolescence $[2,4,5]$. Furthermore, knee pain [6,7], spinal pain [8] and MSK pain in general $[2,9]$ have been shown to be recurrent conditions, and multi-site pain may exist already in adolescence [10-12]. Holden et al. categorised adolescents into

\footnotetext{
*Correspondence: sf@rygklinik.dk

1 Department of Sports Science and Clinical Biomechanics, Faculty of Health Sciences, University of Southern Denmark, Campusvej 55, 5230 Odense M, Denmark

Full list of author information is available at the end of the article
}

four classes describing their pain experience and demonstrated that multi-site pain was more common than pain in a single region [10].

MSK pain in children may have a negative impact on sports participation [13-15], and physical activity in childhood is important for childhood and later health [16], highlighting the importance of optimizing MSK health. In addition, MSK problems in children have been linked to psychological distress [17, 18], poor relations with peers [5, 19], absence from school [13], puberty $[20,21]$ and decreased quality of life $[7,10,22]$. To improve our understanding in this important area, and to

\section{$\triangle B M C$}

(c) The Author(s). 2020 Open Access This article is licensed under a Creative Commons Attribution 4.0 International License, which permits use, sharing, adaptation, distribution and reproduction in any medium or format, as long as you give appropriate credit to the original author(s) and the source, provide a link to the Creative Commons licence, and indicate if changes were made. The images or other third party material in this article are included in the article's Creative Commons licence, unless indicated otherwise in a credit line to the material. If material is not included in the article's Creative Commons licence and your intended use is not permitted by statutory regulation or exceeds the permitted use, you will need to obtain permission directly from the copyright holder. To view a copy of this licence, visit http://creativecommons.org/licenses/by/4.0/ The Creative Commons Public Domain Dedication waiver (http://creativecommons.org/publicdomain/zero/1.0/) applies to the data made available in this article, unless otherwise stated in a credit line to the data. 
learn when and how to intervene, we need more basic epidemiological knowledge about the occurrence and distribution of MSK problems in early life.

MSK pain in different regions of the body (spine, upper extremity (UE) and lower extremity (LE)) has been described in detail in children participating in the Childhood Health, Activity and Motor Performance School Study (CHAMPS Study-DK) [8, 23-26]. LE pain and spinal pain were common and recurrent in the children, whereas UE pain was less common and most often short-lasting [23]. Furthermore, it was found that the frequency of spinal pain increased as the children approached adolescence [8], whereas the frequency of LE pain decreased [23]. The question remains, however, to what extent pain in different body regions overlap in individuals and if specific combinations of pain are prevalent in this age group.

In the current study we therefore aimed to describe the distribution of MSK pain over the course of 1 year in children aged 8 to 16 years, specifically whether MSK pain typically is limited to one region or whether pain presents in more than one region.

Specifically, we wanted to: 1) Categorize children into eight subgroups as having 'no pain'; 'spinal pain only'; 'UE pain only'; 'LE pain only'; 'Spinal and UE pain'; 'Spinal and LE pain'; UE and LE pain'; 'pain in all regions', as well as the proportion of children in each of the eight subgroups, 2) Determine sex and age, number of weeks with pain as well as mean number of episodes, and mean length of episodes for the eight groups.

\section{Method}

\section{Setting}

This was a prospective school-based cohort study nested within the CHAMPS Study-DK [27]. The CHAMPS Study-DK started in 2008 and data collection continued until June 2015. CHAMPS Study-DK is a dynamic cohort study as children could enter and leave the study at any time during the study period, and is described in detail elsewhere [27].

\section{Study population}

In August 2011, pupils attending grades three to seven in 13 out of 17 public primary schools in the municipality of Svendborg, Denmark, were invited to participate in the study, and data until June 2014 (three schoolyears) was used in this paper. Svendborg has 58,000 inhabitants and is comparable to the rest of Denmark in terms of age, sex and income, but has a slightly higher unemployment rate $(5.3 \%$ versus $4.5 \%$ ) [28]. In Svendborg, $84 \%$ of the children attend public schools, and therefore all levels of socioeconomic status were represented.

\section{Data collection}

Information on pain was registered by parent-reported weekly mobile phone text message (SMS) responses. Every week, parents received the following SMS question: 'Has [name of the child] had any pain during the past week in: 1-Neck or back; 2-Shoulder, arm or hand; 3-Hip, leg or foot; or 4-No, [name of the child] did not have any pain.' It was possible to report pain in more than one region. If parents did not reply, they received reminders twice with an interval of $48 \mathrm{~h}$. The SMS question was sent out every week except for 6 weeks during the summer holidays (July and August) and 1 week during the Christmas holidays.

Outcome variables

- No pain the past week $(\mathrm{Y} / \mathrm{N})$

- Spinal pain the past week $(\mathrm{Y} / \mathrm{N})$

- UE pain the past week $(\mathrm{Y} / \mathrm{N})$

- LE pain the past week $(\mathrm{Y} / \mathrm{N})$

\section{Case definitions}

Various terms have been used to describe pain in more than one anatomical region (spine, upper extremity (UE) or lower extremity (LE)). The term 'widespread pain' has traditionally been used to describe pain in more than one region, however this term also includes pain outside of the MSK system such as abdominal pain and/or headache. 'Multisite pain' is traditionally defined as pain in more than one anatomical site, and this can be within the same region, or in different regions. As none of these terms fit the purpose of the analyses in this article, we decided to use the term 'pain in more than one region' when pain was located in more than one region during a school year. The pain does not have to co-exist but can be present at the same or different time-points during a school year.

\section{Statistical analyses}

The children were followed for up to 3 years, and results are reported by school year. To obtain a satisfactory observation period, children should participate in the study for at least a full school year minus 1 week and comply with $85 \%$ or more valid SMS responses. Potential differences in demographics were tested both between participants and non-participants (dropouts or non-consenters) and between compliers and non-compliers (> 15\% missing SMSresponses). For non-participants, only sex was available.

Children were categorized into eight groups for each school year as having either 'No pain'; three groups with pain in one region: 'Spinal pain only', 'UE pain only' or 'LE pain only'; three groups with pain in two regions within a school year: 'Spinal and UE pain', 'Spinal and LE pain' and 'UE and LE pain'; and finally one group with pain from both spine, upper- and lower extremities: 'Pain in all regions'. Proportions of children in each of 
the eight groups were calculated by school year and reported as percentages with $95 \%$ confidence intervals (CI). Each of the eight groups was then described in terms of sex expressed by percentages with $95 \% \mathrm{CI}$ and age with standard deviations (SD). Further for each group, the proportion of weeks with pain during a school year was calculated and expressed by means with 95\% CI.

Length of an episode was defined as consecutive weeks with pain reported in the same region. The number of episodes per child was calculated as the sum of episodes for each child during a school year. Both variables are reported as means with $95 \%$ confidence intervals for each group. Since it is unknown if one single report of pain is of importance or whether a certain duration is needed to influence the life of the children, all analyses were performed using two different definitions, i.e. 'At least 1 pain week' and 'At least 3 pain weeks' during one schoolyear.

\section{Missing SMS responses}

If four or fewer consecutive SMS responses were missing, they were imputed with the same value as the previous week's response, provided that the response was the same for the week after the missing response(s). Otherwise, we defined the end of that episode as occurring at the week prior to the missing response. If there were more than four consecutive missing SMS responses, we also defined the end of the episode as occurring at the week prior to the first missing SMS response. A sensitivity analysis was performed to estimate the impact of these decision rules by treating missing SMS responses in two extreme ways to determine the range within which the correct value would lie: First, we coded missing SMS response to be the same as the last SMS response, regardless of the value of the next response, which would potentially inflate episode lengths and diminish the number of episodes. Second, we coded SMS responses as 'no pain' for all weeks with missing SMS responses, which would do the opposite.

STATA 15.0 (StataCorp, College Station, Texas, USA) was used for the analyses. Significance level was set at 0.05 , and statistically tests were not used but significant differences was found by the use of overlapping CIs.

\section{Results}

Study sample

From August 2011 to June 2014, 1917 children were invited to participate in the CHAMPS Study-DK, and 1465 (76\%) children were enrolled. During this period 296 children dropped out (Fig. 1).

The average weekly response rate for all three school years was $96 \%$. After excluding children with low SMS

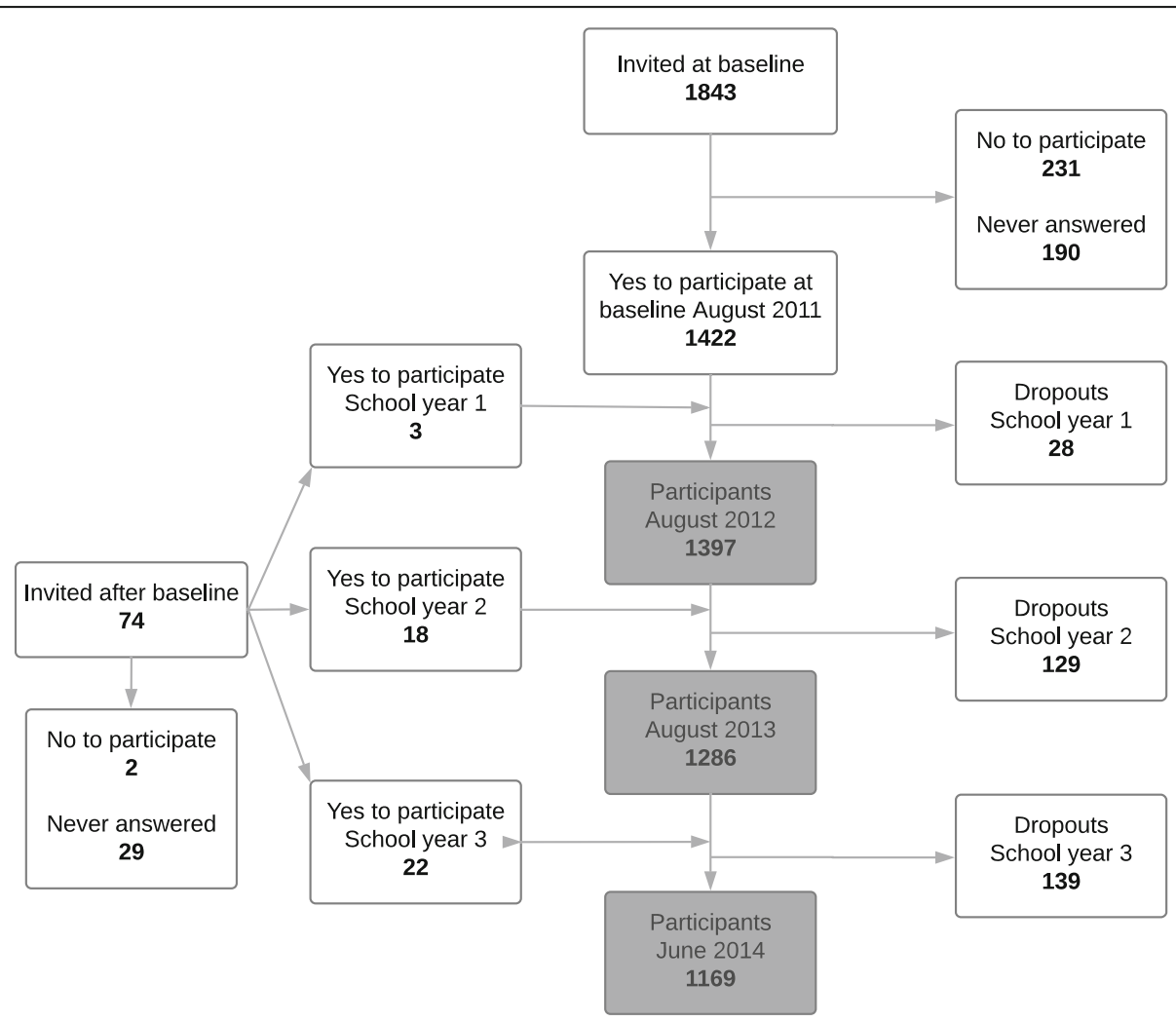

Fig. 1 Overview of the participant flow in a cohort of Danish school children (CHAMPS Study-DK; $n=1465$ ) 
compliance, the final sample consisted of 982 children in school year 1, 1100 children in school year 2 and 1033 children in school year 3 (Fig. 2). The total number of SMS responses was 43,$171 ; 51,641$ and 47,495 for the three school years, respectively.

In August 2011, children were 8 to 14 years of age (mean 10.7 (SD 1.4)), and during all three school years, $52 \%$ were girls (Table 1 ).

About 30\% of the children did not experience any pain during a school year (Table 1). When reporting pain it was most frequently in the LEs, $53.1 \%$ (95\% CI 50.1; 56.2) to $60.1 \%$ (95\% CI $57.0 ; 63.1$ ), whereas they least frequently reported pain in the UEs, $22.0 \%(95 \%$ CI $19.6 ; 24.6)$ to $23.8 \%$ (95\% CI 21.4; 26.4).

There were no significant differences between the children who declined participation, had low SMS compliance or dropped out when compared to the study sample in relation to sex, but the dropouts were on average older than the children who remained in the study (12.5 versus 10.6 years of age at baseline, $p<0.001$ ).

\section{Pain patterns}

Findings are presented in detail for school year 1, followed by a description of differences for schoolyear 2 and 3. Tables and figures with detailed information pertaining to school years 2 and 3 can be seen in Additional file 1.

\section{Results for 'At least one pain week' during a school year Distribution of children into eight pain groups}

Using this definition, $28.5 \%$ of the children did not experience pain during school year 1 . The $71.5 \%$ of the children who did experience pain, most commonly did so in the LE
(60.0\%), followed by spinal pain (28.7\%), and the UE (22.6\%). For those reporting pain, it was most commonly in one region only (39.2\%) and most often in the LE (29.5\%). Among those reporting pain, pain in more than one region was, however, also common (32.2\%), most commonly spinal and LE pain (13.2\%). The distribution of the subgroups is shown in Fig. 3a.

These patterns remained for the other two school years with 72.9 and $69.2 \%$ reporting pain during year 2 and 3 , respectively, LE pain being most common, and about one third reporting pain at more than one site (Add. file 1).

\section{Sex}

In school year 1, boys reported more LE pain only than girls, whereas the girls reported more spinal pain and UE pain. Pain at two sites was approximately equally distributed between the two sexes, whereas pain at all three sites was more common in girls (Fig. 3a).

The sex difference for the group with pain at all three sites remains across the 3 years, but other differences in sex distribution become progressively smaller over the three-year period (Add. file 1).

\section{Age}

Generally, there were no differences in mean age between the sub-groups (Table 2 and Add. file 1).

\section{Proportion of weeks with pain}

Overall, the children reporting pain from more sites reported pain more often than children with pain at only one site. Indeed, the total proportion of pain weeks approached the sum of weeks from individual pain sites,

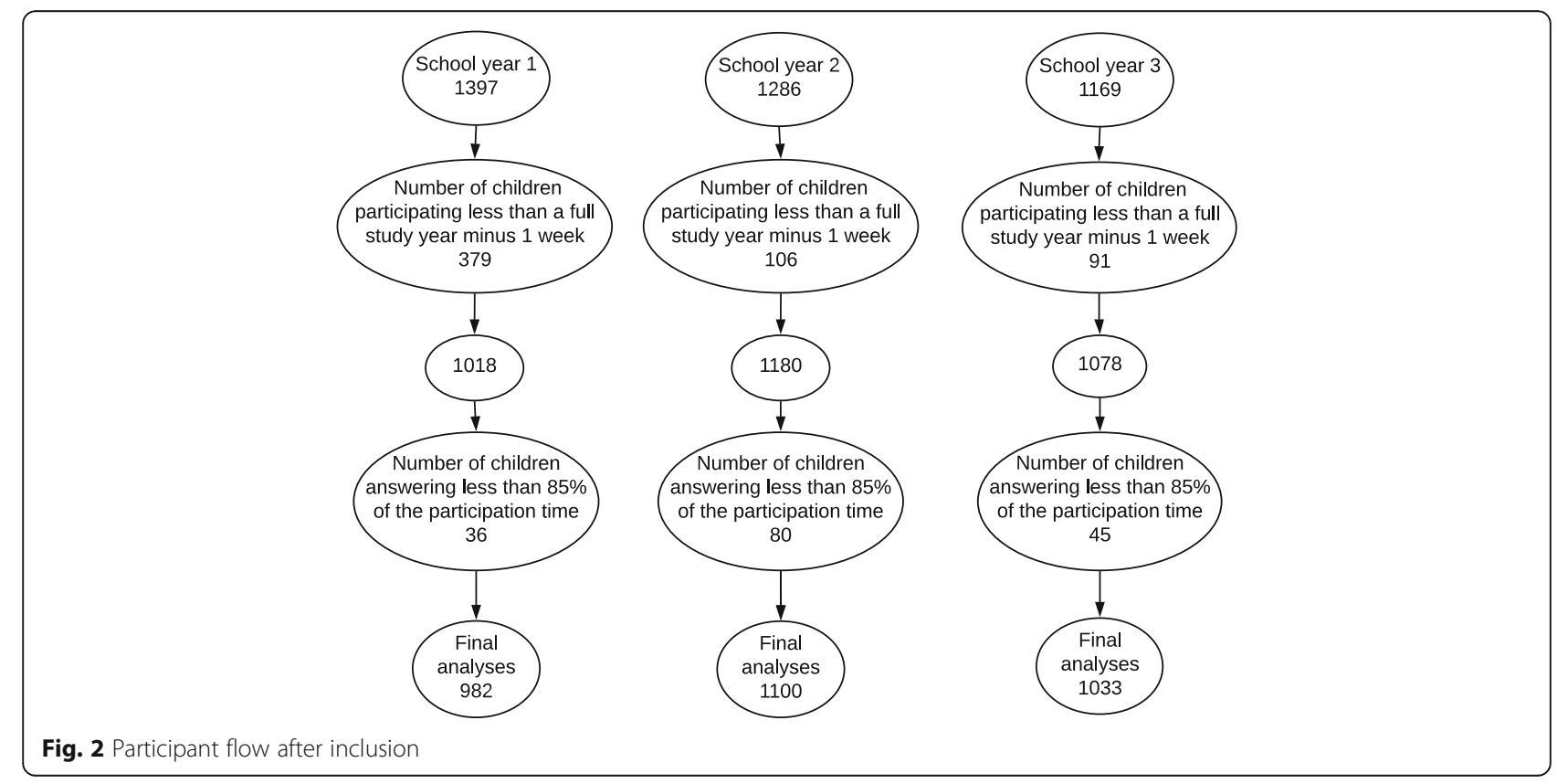


Table 1 Age, sex and pain prevalence by school year in a cohort of Danish school children (CHAMPS Study-DK)

\begin{tabular}{llll}
\hline & $\begin{array}{l}\text { School year 1 } \\
\text { (August 2011 to June 2012) }\end{array}$ & $\begin{array}{l}\text { School year 2 } \\
\text { (August 2012 to June 2013) }\end{array}$ & $\begin{array}{l}\text { School year 3 } \\
\text { (August 2013 to June 2014) }\end{array}$ \\
\hline Total & $982(100.0)$ & $1100(100.0)$ & $1033(100.0)$ \\
Girls, n (\%) & $512(52.1)$ & $576(52.4)$ & $539(52.2)$ \\
Mean age, years (SD) & $10.7($ SD 1.4) & $11.6($ SD 1.4) & $12.5($ SD 1.4) \\
Spinal pain, \% (95\% Cl) & $28.8(26.1 ; 31.7)$ & $33.6(30.9 ; 36.5)$ & $31.2(28.4 ; 34.1)$ \\
Upper extremity pain, \% (95\% Cl) & $22.6(20.1 ; 25.3)$ & $23.8(21.4 ; 26.4)$ & $22.0(19.6 ; 24.6)$ \\
Lower extremity pain, \% (95\% Cl) & $60.1(57.0 ; 63.1)$ & $58.3(55.3 ; 61.2)$ & $53.1(50.1 ; 56.2)$ \\
No pain, \% $(95 \% \mathrm{Cl})$ & $28.5(25.8 ; 31.4)$ & $27.1(24.5 ; 29.8)$ & $30.8(28.0 ; 33.7)$ \\
\hline
\end{tabular}

a) At least one week with pain

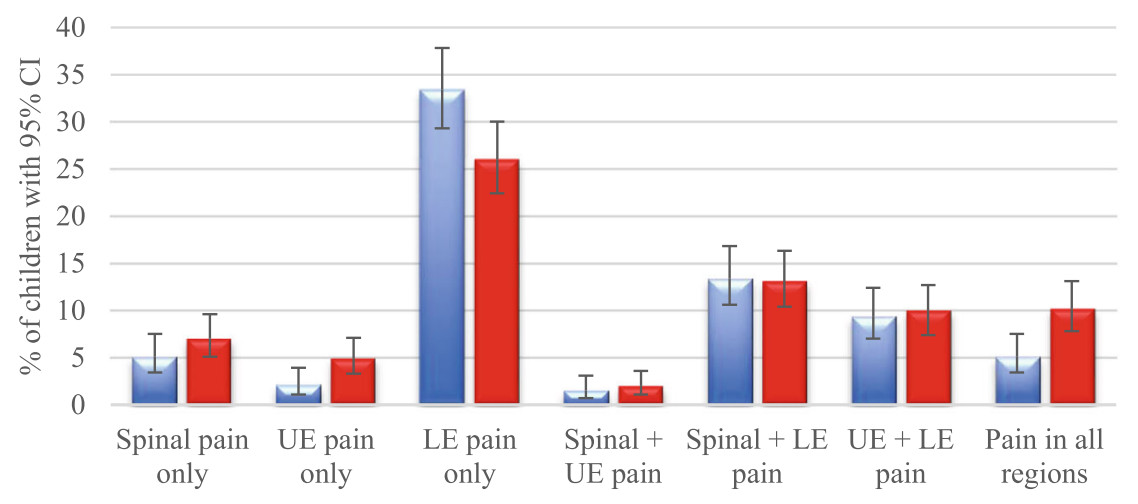

$\square$ boys with at least one pain week in each site during school year $1(\mathrm{n}=470)$

घirls with at least one pain week in each site during school year $1(\mathrm{n}=512)$

b) At least three weeks with pain

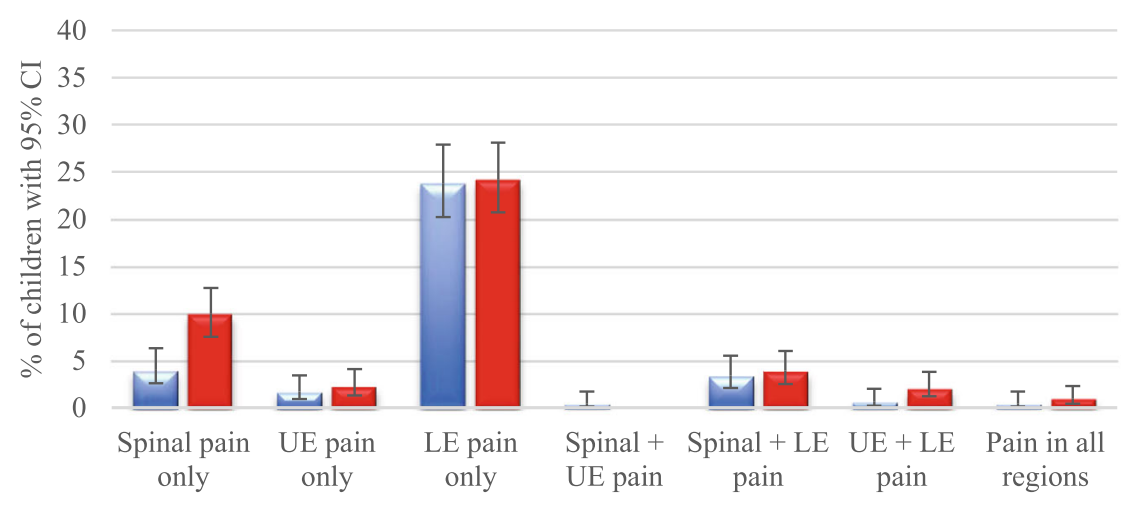

$\square$ boys with at least three pain weeks in each site during school year $1(\mathrm{n}=470)$

girls with at least three pain weeks in each site during school year $1(\mathrm{n}=512)$

Fig. 3 Proportion of Danish children aged 8 to 16 years with either a) at least 1 week with pain or b) at least 3 weeks with pain in each anatomical region during school year 1. Presented by sex and with $95 \%$ confidence interval (CI). UE: upper extremity, LE: lower extremity 
Table 2 Description of Danish children aged 8 to 16 years during school year 1 . Reported by pain group. Pain was defined as at least one pain week from a body region during a school year

\begin{tabular}{|c|c|c|c|c|c|c|}
\hline Pain site(s) & $\begin{array}{l}\text { Proportion } \\
\%(95 \% \mathrm{Cl})\end{array}$ & $\begin{array}{l}\text { Age } \\
\text { Years (SD) }\end{array}$ & $\begin{array}{l}\text { Sex } \\
\% \text { female }\end{array}$ & $\begin{array}{l}\text { Weeks with pain } \\
\%(95 \% \mathrm{Cl})\end{array}$ & Number of episodes (95\%Cl) & $\begin{array}{l}\text { Length of episodes } \\
\text { Weeks }(95 \% \mathrm{Cl})\end{array}$ \\
\hline No pain $(n=279)$ & $28.5(25.7 ; 31.3)$ & $10.6(1.5)$ & 49.6 & 0 & 0 & - \\
\hline SP only $(n=60)$ & $6.1(4.6 ; 7.6)$ & $11.0(1.3)$ & 60.0 & $15.4(9.6 ; 21.3)$ & $1.8(1.4 ; 2.1)$ & $3.9(2.5 ; 5.3)$ \\
\hline UEP only $(n=35)$ & $3.6(2.4 ; 4.8)$ & $10.4(1.4)$ & 71.4 & $6.2(3.2 ; 9.3)$ & $1.2(1.0 ; 1.4)$ & $2.3(1.5 ; 3.1)$ \\
\hline LEP only $(n=290)$ & $29.5(26.7 ; 32.4)$ & $10.6(1.4)$ & 45.9 & $18.4(15.7 ; 21.0)$ & $2.3(2.1 ; 2.5)$ & $3.5(3.1 ; 4.0)$ \\
\hline $\operatorname{SP}+\operatorname{UEP}(n=16)$ & $1.7(0.9 ; 2.5)$ & $10.6(1.2)$ & 58.2 & $19.4(6.3 ; 32.4)$ & & \\
\hline SP & & & & $15.4(1.9 ; 28.9)$ & $1.7(1.2 ; 2.2)$ & $4.0(0.6 ; 7.3)$ \\
\hline UEP & & & & $6.7(2.3 ; 11.1)$ & $1.2(0.8 ; 1.4)$ & $2.5(0.9 ; 4.1)$ \\
\hline $\operatorname{SP}+\operatorname{LEP}(n=129)$ & $13.2(11.1 ; 15.3)$ & $10.8(1.4)$ & 51.5 & $26.9(22.9 ; 31.0)$ & & \\
\hline SP & & & & $11.7(8.7 ; 14.7)$ & $1.8(1.6 ; 2.0)$ & $2.9(2.3 ; 3.4)$ \\
\hline LEP & & & & $18.3(14.5 ; 22.0)$ & $2.6(2.3 ; 3.0)$ & $3.1(2.6 ; 3.5)$ \\
\hline UEP+LEP $(n=94)$ & $9.6(7.8 ; 11.4)$ & $10.8(1.3)$ & 53.2 & $24.1(19.9 ; 28.3)$ & & \\
\hline UEP & & & & $6.2(5.0 ; 7.5)$ & $1.4(1.2 ; 1.6)$ & $2.0(1.7 ; 2.3)$ \\
\hline LEP & & & & $18.8(14.7 ; 22.9)$ & $2.8(2.4 ; 3.2)$ & $2.9(2.5 ; 3.4)$ \\
\hline SP+UEP+LEP $(n=75)$ & $7.7(6.0 ; 9.4)$ & $11.0(1.3)$ & 68.4 & $40.2(24.4 ; 46.1)$ & & \\
\hline SP & & & & $14.7(9.7 ; 19.7)$ & $2.1(1.8 ; 2.5)$ & $3.2(2.2 ; 3.8)$ \\
\hline UEP & & & & $7.2(5.5 ; 8.9)$ & $1.6(1.4 ; 1.9)$ & $1.9(1.6 ; 2.2)$ \\
\hline LEP & & & & $22.4(17.6 ; 27.1)$ & $3.4(2.4 ; 3.4)$ & $2.9(2.4 ; 3.4)$ \\
\hline
\end{tabular}

SP spinal pain, LEP lower extremity pain, UEP Upper extremity pain, $\mathrm{Cl}$ confidence interval, SD standard deviation

suggesting limited overlap of pain, i.e. in many cases the pain from different sites did not occur simultaneously (Table 2).

Generally, these patterns remained for the other two school years (Add. file 1).

\section{Number and length of pain episodes}

In year 1, pain from the LE occurred most often either alone or in combination with pain from other sites with 2.8 to 3.4 episodes during school year 1 , depending on group. Spinal pain was responsible for the longest episodes with episode lengths from 2.9 to 4.0 weeks, depending on group. Thus, pain from the UE represented the fewest recurrences and the shortest episode duration (Table 2).

For the two following years, LE remained the most common area with pain. In year 2, spinal pain episodes were the longest in all groups except for the group with pain at all three sites where LE pain episodes were longer. For year 3, there was no consistent pattern for length of episodes (Add. file 1).

\section{Results for 'At least three pain weeks' during a school year}

\section{Distribution of children into eight pain groups}

Using this definition, $39.1 \%$ of the children experienced pain during school year 1 . The most common pain site was again the LE (29.8\%), followed by spinal pain (11.6\%), and UE (4.3\%). One third of the children had pain in one region only, most commonly in the LEs (24.0\%). Only $6.0 \%$ of the children experienced pain in more than one region, again with 'Spinal and LE pain' as the most frequent pain combination (3.7\%). The distribution of the subgroups is shown in Fig. 3b.

These patterns remained for the other two school years with 37.7 and $36.9 \%$ reporting pain during year 2 and 3 , respectively, LE pain being most common, and $7 \%$ reporting pain at more than one site (Add. file 1 ).

\section{Sex}

Most pain groups were small, which makes an investigation of sex differences difficult. However, a distinct difference could be observed for spinal pain only with a higher frequency in girls (Fig. 3b).

In year 2 and 3 , there were more boys than girls with LE pain only, while the girls again were most prevalent in all other groups. Differences were small and not statistically significant (Add. file 1).

\section{Age}

Generally, there were no differences in mean age between the sub-groups (Table 3 and Add. file 1).

\section{Proportion of weeks with pain}

Again, the children with pain from more sites reported pain about twice as often compared to children with pain at only one site. (Table 3 ). 
Table 3 Description of Danish children aged 8 to 16 years during school year 1. Reported by pain group. Pain was defined as at least three pain weeks from a body region during a school year

\begin{tabular}{|c|c|c|c|c|c|c|}
\hline Pain site(s) & $\begin{array}{l}\text { Proportion } \\
\%(95 \% \mathrm{Cl})\end{array}$ & $\begin{array}{l}\text { Age } \\
\text { Years (SD) }\end{array}$ & $\begin{array}{l}\text { Sex } \\
\% \text { female }\end{array}$ & $\begin{array}{l}\text { Weeks with pain } \\
\%(95 \% \mathrm{Cl})\end{array}$ & Number of episodes $(95 \% \mathrm{Cl})$ & $\begin{array}{l}\text { Length of episodes } \\
\text { Weeks }(95 \% \mathrm{Cl})\end{array}$ \\
\hline No pain $(n=598)$ & $60.9(57.0 ; 63.9)$ & $10.6(1.4)$ & 48.5 & 0 & 0 & - \\
\hline SP only $(n=69)$ & $7.0(5.6 ; 8.8)$ & $11.1(1.4)$ & 72.5 & $25.0(19.3 ; 30.8)$ & $2.4(2.1 ; 2.8)$ & $4.5(3.4 ; 5.6)$ \\
\hline UEP only $(n=20)$ & $2.0(1.3 ; 3.1)$ & $11.1(1.3)$ & 60.0 & $18.7(14.5 ; 22.8)$ & $2.6(1.8 ; 3.4)$ & $3.2(2.4 ; 4.0)$ \\
\hline LEP only $(n=236)$ & $24.0(21.5 ; 26.8)$ & $10.8(1.3)$ & 52.5 & $33.8(30.7 ; 36.8)$ & $3.6(3.3 ; 3.9)$ & $4.1(3.8 ; 4.5)$ \\
\hline $\mathrm{SP}+\mathrm{UEP}(n=2)$ & $0.2(0.1 ; 0.8)$ & $10.5(0.7)$ & 0 & $58.0(-)$ & & \\
\hline SP & & & & $54.5(-)$ & $2(-)$ & $12(-)$ \\
\hline UEP & & & & $22.7(-)$ & $2(-)$ & $5(-)$ \\
\hline $\mathrm{SP}+\mathrm{LEP}(n=36)$ & $3.7(2.7 ; 5.0)$ & $11.1(1.2)$ & 55.6 & $51.3(43.5 ; 59.1)$ & & \\
\hline SP & & & & $31.9(23.4 ; 40.3)$ & $3.3(2.6 ; 3.9)$ & $4.3(3.6 ; 4.8)$ \\
\hline LEP & & & & $30.4(23.0 ; 37.9)$ & $4.1(3.6 ; 4.8)$ & $3.3(2.5 ; 4.1)$ \\
\hline UEP + LEP $(n=14)$ & $1.4(0.8 ; 2.4)$ & $10.5(1.3)$ & 78.6 & $48.1(37.1 ; 59.1)$ & & \\
\hline UEP & & & & $16.6(12.1 ; 21.0)$ & $1.9(1.4 ; 2.4)$ & $3.9(2.7 ; 5.2)$ \\
\hline LEP & & & & $35.6(23.7 ; 47.6)$ & $4.0(2.9 ; 5.1)$ & $3.9(2.6 ; 5.2)$ \\
\hline SP+UEP+LEP $(n=7)$ & $0.7(0.3 ; 1.5)$ & $11.1(1.2)$ & 71.4 & $75.0(60.8 ; 89.1)$ & & \\
\hline SP & & & & $38.0(9.3 ; 66.7)$ & $4.3(2.7 ; 5.9)$ & $3.9(2.1 ; 5.7)$ \\
\hline UEP & & & & $19.5(10.5 ; 28.6)$ & $3.0(1.4 ; 4.6)$ & $2.9(2.1 ; 3.6)$ \\
\hline LEP & & & & $30.8(9.3 ; 52.2)$ & $3.7(2.7 ; 4.7)$ & $3.6(1.1 ; 6.2)$ \\
\hline
\end{tabular}

SP spinal pain, LEP lower extremity pain, UEP Upper extremity pain, Cl confidence interval, SD standard deviation

No additional information could be derived from the other two school years (Add. file 1).

\section{Number and length of pain episodes}

Most children reported pain from the LE with 3.6 to 4.1 episodes during school year 1, depending on group. Spinal pain was responsible for the longest episodes with episode lengths from 3.9 to 4.5 weeks, depending on group. Thus again, pain from the UE represented the fewest recurrences and the shortest episode duration (Table 3).

For the two following years, LE pain was also the most frequent, but there was no consistent pattern for length of episodes (Add. file 1).

\section{Missing SMS responses}

Overall, our data imputation schemes did not change the results of any of the analyses (Additional file 2).

\section{Discussion}

\section{Summary of findings}

In a 3-year cohort study of Danish school children aged 8 to 14 years at baseline, we found that children with pain most frequently reported pain in one region, most frequently in the LE, however, many children reported pain in more than one region during a school year.
When pain was defined as 'at least one pain week in each region during a school year', $30 \%$ reported pain in more than one region versus only $6 \%$ when pain was defined as 'at least three pain weeks in each region during a school year' indicating that most episodes were of short duration. About 70\% reported at least 1 week with pain during a school year and 30\% reported at least 3 weeks. Most children with spinal pain or with pain in more than one region were girls.

\section{Comparison to previous literature}

We found that during a school year around 30\% of the children reported at least one pain week in more than one region, which is higher when compared to two other school-based cohort studies. Holden et al. found that about 20\% had 'Multisite bodily pain' [10] based on selfreported data for point prevalence, which is expected to be lower than in the current study, based on 1 year prevalence. This might have been partly counterbalanced by data in our study being parentally reported, since parents appear to report lower prevalence rates of pain than the children themselves [29].

Approximately $6 \%$ of the children reported pain in more than one region lasting at least 3 weeks during a school year, which is similar to findings in two other studies [30, 31]. Hoftun et al. found MSK pain in at least three anatomical pain sites in $8.5 \%$ of adolescents aged 13 to 19 years [30] and Mikkelsson et al. found the 
prevalence of widespread pain that was not exclusively musculoskeletal pain increasing from $7 \%$ in children aged $10-12$ years, $9 \%$ when children were $11-13$ years, to $15 \%$ in children aged 14 to 16 years [31]. In both studies somewhat different duration and frequency of pain were used, however, despite our lenient definition of pain, the affected children reported pain in about $50 \%$ of the weeks or more during a school year and thus the pain definitions may be comparable.

We found that the majority of children with pain in more than one region were girls, which is similar to findings from other studies $[4,10,30-32]$.

\section{Strengths and weaknesses}

In this study, parents reported on behalf of the children, which may bias results. However participating children, when asked, more often reported pain that was not reported by their parents, whereas the opposite was rarely the case, according to a validity study nested within the CHAMPS Study-DK [33]. Thus, our estimates are probably conservative when compared to studies relying on child-reported data. Concordance was better for pain of greater intensity, indicating that parents did not report minor pain, which was also reported by Sundblad et al. [29], whereas better concordance was found when children were more severely ill [34]. Potentially, this is a limitation in this study, if parents also were reluctant to report secondary pain of short duration.

When pain was defined as at least 1 week in each region during a school year, around 30\% reported pain in more than one region, versus $6 \%$ if at least 3 pain weeks in each region was needed. Thus, it may be argued that the difference in proportion between these two groups would be smaller if parents were reluctant to report secondary pain of short duration.

Data collection via mobile phone text messages is known to be practical and user-friendly $[35,36]$ with responses comparable to telephone interviews [35]. An expected limitation was that parents answered SMS questions continuously every week for more than 5 years, and therefore some response fatigue could have occurred. However, this did not seem to be the case since the response rate was high and did not decrease during the study period.

Major strengths of this study include the large prospective population-based cohort, the high response rate of the text messages, and the short recall period.

\section{Implications}

Many children report pain in more than one body region during a school year. Whether the different pain regions are to be regarded as individual entities or part of a more general MSK syndrome, is still unknown. Some degree of overlap is to be expected by chance, and it is known from studies of both adolescent and adult populations, that disorders tend to cluster in some individuals $[37,38]$. In adolescents it has been found that pain in one part of the spine increased the risk of experiencing pain in other parts within the following 2 years, so it is also possible that MSK pain in one region increases the risk of pain in other regions [39].. This could have clinical implications, as knowledge of such a sequence will increase the incentive to implement treatment at the initial stage of the potential cascade. Therefore, an interesting next step could be to map the sequences of pain appearance to potentially identify the optimal time and body region with regard to prevention and early effective treatment.

\section{Conclusion}

Danish schoolchildren often experienced pain at more than one pain site during a schoolyear, and a significantly larger proportion of girls than boys reported pain in all three regions. This could indicate that, at least in some instances, the musculoskeletal system should be regarded as one entity, both for clinical and research purposes.

\section{Supplementary information}

Supplementary information accompanies this paper at https://doi.org/10. 1186/s12998-020-00330-9.

Additional file 1. Illustrations with information about school years 2 and 3

Additional file 2. Sensitivity analyses of missing data. Primary data: pain defined as at least one pain week in each site during school year 1. $n=$ 982, of which 280 children did not report pain. Sensitivity analyses of missing data. Primary data: pain were defined as at least three pain weeks within school year 1. $n=982$, of which 598 children did not report pain.

Abbreviations

CHAMPS Study-DK: Childhood Health, Activity and Motor Performance School Study; Cl: Confidence interval; LE: Lower extremity;

MSK: Musculoskeletal; SMS: Mobile phone text message; UE: Upper extremity

\section{Acknowledgements}

We acknowledge the participants and their parents, the participating schools and 'Sport \& Uddannelse Svendborg Kommune', and all members of the CHAMPS Study-DK. Furthermore, we would like to acknowledge Niels Wedderkopp for the design and leading the CHAMPS Study-DK.

\section{Authors' contributions}

SF, KBD and TJ participated in the collection of data. LH, WV and SF conceived the study idea. SF prepared the data for the statistical analyses, and SF conducted those with assistance from WV, SF, WV, JH and LH participated in the interpretation of the results and for the first draft of the manuscript. All authors read, commented, discussed and approved the final version of the manuscript.

\section{Funding}

The authors gratefully acknowledge the following organisations for funding individual researchers and for funding the CHAMPS Study Denmark part II: the Nordea Foundation, the TRYG Foundation, the IMK Foundation, the Region of Southern Denmark, the University of Southern Denmark, the University College Lillebaelt's Department of Physiotherapy, the Danish 
Chiropractic Research Foundation, the Svendborg Project, the Municipality of Svendborg, as well as the Nordic Institute of Chiropractic and Clinical Biomechanics.

\section{Availability of data and materials}

Data are available only upon request from the CHAMPS Study-DK Steering Committee due to legal and ethical restrictions. Interested parties may contact Dr. Niels Wedderkopp (nwedderkopp@health.sdu.dk) and the following information will be required at the time of application: a description of how the data will be used, securely managed, and permanently deleted.

\section{Ethics approval and consent to participate}

Approval was obtained from the Regional Health Research Ethics Committee before start (ID: S20080047) and the study was registered with the Danish Data Protection Agency (J.nr. 2008-41-2240). Written informed consent was obtained from the parents. Prior to clinical examinations, both child and parent gave verbal acceptance. All participation was voluntary with the option to withdraw at any time.

\section{Content of publication}

Written informed consent was obtained from the participants.

\section{Competing interests}

The authors declare that they have no competing interests.

\section{Author details}

${ }^{1}$ Department of Sports Science and Clinical Biomechanics, Faculty of Health Sciences, University of Southern Denmark, Campusvej 55, 5230 Odense M, Denmark. ${ }^{2}$ Department of Orthopaedics and Traumatoloy, University Hospital Basel, Spitalstr 21, CH-4031 Basel, Switzerland. ${ }^{3}$ Institute for Medical Biometry and Statistics, Medical Faculty and Medical Center, University of Freiburg, Freiburg, Germany. ${ }^{4}$ Nordic Institute of Chiropractic and Clinical Biomechanics, Campusvej 55, 5230 Odense M, Denmark. ${ }^{5}$ Health Sciences Research Centre, University College Lillebaelt, Niels Bohrs allé 1, 5230 Odense M, Denmark

Received: 19 December 2019 Accepted: 9 June 2020

\section{Published online: 04 August 2020}

\section{References}

1. El-Metwally A, Salminen JJ, Auvinen A, Macfarlane G, Mikkelsson M. Risk factors for development of non-specific musculoskeletal pain in preteens and early adolescents: a prospective 1-year follow-up study. BMC Musculoskelet Disord. 2007:8:46.

2. Perquin CW, Hazebroek-Kampschreur AA, Hunfeld JA, Bohnen AM, van Suijlekom-Smit LW, Passchier J, van der Wouden JC. Pain in children and adolescents: a common experience. Pain. 2000;87(1):51-8.

3. Jeffries LJ, Milanese SF, Grimmer-Somers KA. Epidemiology of adolescent spinal pain: a systematic overview of the research literature. Spine (Phila Pa 1976). 2007;32(23):2630-7.

4. Rathleff MS, Roos EM, Olesen $J$, Rasmussen S. High prevalence of daily and multi-site pain--a cross-sectional population-based study among 3000 Danish adolescents. BMC Pediatr. 2013;13:191.

5. Haraldstad K, Sorum R, Eide H, Natvig GK, Helseth S. Pain in children and adolescents: prevalence, impact on daily life, and parents' perception, a school survey. Scand J Caring Sci. 2011;25(1):27-36.

6. Rathleff MS, Rathleff CR, Olesen $J \mathrm{~L}$, Rasmussen $\mathrm{S}$, Roos EM. Is knee pain during adolescence a self-limiting condition? Prognosis of Patellofemoral pain and other types of knee pain. Am J Sports Med. 2016;44(5):1165-71.

7. Rathleff MS, Holden S, Straszek CL, Olesen JL, Jensen MB, Roos EM. Five-year prognosis and impact of adolescent knee pain: a prospective populationbased cohort study of 504 adolescents in Denmark. BMJ Open. 2019;9(5): e024113.

8. Dissing KB, Hestbaek L, Hartvigsen J, Williams C, Kamper S, Boyle E, Wedderkopp N. Spinal pain in Danish school children - how often and how long? The CHAMPS Study-DK. BMC Musculoskelet Disord. 2017;18(1):67.

9. King S, Chambers CT, Huguet A, MacNevin RC, McGrath PJ, Parker L, MacDonald AJ. The epidemiology of chronic pain in children and adolescents revisited: a systematic review. Pain. 2011;152(12):2729-38.

10. Holden S, Rathleff MS, Roos EM, Jensen MB, Pourbordbari N, Graven-Nielsen T. Pain patterns during adolescence can be grouped into four pain classes with distinct profiles: A study on a population based cohort of 2953 adolescents. Eur J Pain. 2018:22(4):793-799. https://doi.org/10.1002/ejp.1165.

11. Swain MS, Henschke N, Kamper SJ, Gobina I, Ottova-Jordan V, Maher CG. An international survey of pain in adolescents. BMC Public Health. 2014;14:447.

12. Paananen MV, Taimela SP, Auvinen JP, Tammelin TH, Kantomaa MT, Ebeling HE, Taanila AM, Zitting PJ, Karppinen JI. Risk factors for persistence of multiple musculoskeletal pains in adolescence: a 2-year follow-up study. Eur J Pain. 2010;14(10):1026-32.

13. Kamper SJ, Henschke N, Hestbaek L, Dunn KM, Williams CM. Musculoskeletal pain in children and adolescents. Braz J Phys Ther. 2016;20(3):275-84.

14. Swain MS, Henschke N, Kamper SJ, Gobina I, Ottova-Jordan V, Maher CG. Pain and moderate to vigorous physical activity in adolescence: an international population-based survey. Pain Med. 2016;17(5):813-9.

15. Roth-Isigkeit A, Thyen U, Stoven H, Schwarzenberger J, Schmucker P. Pain among children and adolescents: restrictions in daily living and triggering factors. Pediatrics. 2005;115(2):e152-62.

16. Janssen I, Leblanc AG. Systematic review of the health benefits of physical activity and fitness in school-aged children and youth. Int J Behav Nutr Phys Act. 2010;7:40.

17. Stallknecht SE, Strandberg-Larsen K, Hestbaek L, Andersen AN. Spinal pain and co-occurrence with stress and general well-being among young adolescents: a study within the Danish National Birth Cohort. Eur J Pediatr. 2017;176(6):807-14.

18. Diepenmaat AC, van der Wal MF, de Vet HC, Hirasing RA. Neck/shoulder, low back, and arm pain in relation to computer use, physical activity, stress, and depression among Dutch adolescents. Pediatrics. 2006;117(2):412-6.

19. El-Metwally A, Salminen JJ, Auvinen A, Kautiainen H, Mikkelsson M. Risk factors for traumatic and non-traumatic lower limb pain among preadolescents: a population-based study of Finnish schoolchildren. BMC Musculoskelet Disord. 2006;7:3

20. Hebert JJ, Leboeuf-Yde C, Franz C, et al. Pubertal development and growth are prospectively associated with spinal pain in young people (CHAMPS study-DK). Eur Spine J. 2019;28(7):1565-71. https://doi.org/10.1007/s00586019-05905-6.

21. Wedderkopp N, Andersen LB, Froberg K, Leboeuf-Yde C. Backpain reporting in young girls appears to be puberty-related. BMC MusculoskeletDisord. 2005;6:52.

22. Smith A, Beales D, O'Sullivan P, Bear N, Straker L. Low Back pain with impact at 17 years of age is predicted by early adolescent risk factors from multiple domains: analysis of the Western Australian pregnancy cohort (Raine) study. J Orthop Sports Phys Ther. 2017:47(10):752-62.

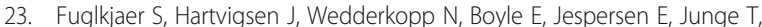
Larsen LR, Hestbaek L. Musculoskeletal extremity pain in Danish school children - how often and for how long? The CHAMPS study-DK. BMC Musculoskelet Disord. 2017;18(1):492.

24. Jespersen E, Rexen CT, Franz C, Moller NC, Froberg K, Wedderkopp N. Musculoskeletal extremity injuries in a cohort of schoolchildren aged 6-12: a 2.5-year prospective study. Scand J Med Sci Sports. 2015;25(2):251-8.

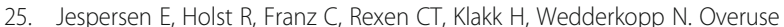
and traumatic extremity injuries in schoolchildren surveyed with weekly text messages over 2.5 years. Scand J Med Sci Sports. 2014;24(5):807-13.

26. Franz C, Wedderkopp N, Jespersen E, Rexen CT, Leboeuf-Yde C. Back pain in children surveyed with weekly text messages - a 2.5 year prospective school cohort study. Chiropr Man Ther. 2014;22(1):35

27. Wedderkopp N, Jespersen E, Franz C, Klakk H, Heidemann M, Christiansen C, Moller NC, Leboeuf-Yde C. Study protocol. The Childhood Health, Activity, and Motor Performance School Study Denmark (The CHAMPS-study DK). BMC Pediatr. 2012;12:128.

28. Statistics Denmark [http://www.statistikbanken.dk]

29. Sundblad GM, Saartok T, Engstrom LM. Child-parent agreement on reports of disease, injury and pain. BMC Public Health. 2006;6:276.

30. Hoftun GB, Romundstad PR, Zwart JA, Rygg M. Chronic idiopathic pain in adolescence--high prevalence and disability: the young HUNT study 2008 Pain. 2011;152(10):2259-66.

31. Mikkelsson M, El-Metwally A, Kautiainen H, Auvinen A, Macfarlane GJ, Salminen JJ. Onset, prognosis and risk factors for widespread pain in schoolchildren: a prospective 4-year follow-up study. Pain. 2008;138(3):681-7.

32. Adamson G, Murphy S, Shevlin M, Buckle P, Stubbs D. Profiling schoolchildren in pain and associated demographic and behavioural factors: a latent class approach. Pain. 2007;129(3):295-303.

33. Kamper SJ, Dissing KB, Hestbaek L. Whose pain is it anyway? Comparability of pain reports from children and their parents. Chiropr Man Therap. 2016; $24: 24$ 
34. Mock C, Acheampong F, Adjei S, Koepsell T. The effect of recall on estimation of incidence rates for injury in Ghana. Int J Epidemiol. 1999;28(4): 750-5.

35. Johansen B, Wedderkopp N. Comparison between data obtained through real-time data capture by SMS and a retrospective telephone interview. Chiropr Osteopat. 2010;18:10.

36. Axen I, Bodin L, Bergstrom G, Halasz L, Lange F, Lovgren PW, Rosenbaum A, Leboeuf-Yde C, Jensen I. The use of weekly text messaging over 6 months was a feasible method for monitoring the clinical course of low back pain in patients seeking chiropractic care. J Clin Epidemiol. 2012;65(4):454-61.

37. Holden S, Rathleff MS, Roos EM, Jensen MB, Pourbordbari N, Graven-Nielsen T. Pain patterns during adolescence can be grouped into four pain classes with distinct profiles: a study on a population based cohort of 2953 adolescents. Eur J Pain. 2018;22(4):793-9.

38. Hartvigsen J, Davidsen M, Hestbaek L, Sogaard K, Roos EM. Patterns of musculoskeletal pain in the population: a latent class analysis using a nationally representative interviewer-based survey of 4817 Danes. Eur J Pain. 2013;17(3):452-60

39. Aartun E, Hartvigsen J, Wedderkopp N, Hestbaek L. Spinal pain in adolescents: prevalence, incidence, and course: a school-based two-year prospective cohort study in 1,300 Danes aged 11-13. BMC Musculoskelet Disord. 2014:15:187.

\section{Publisher's Note}

Springer Nature remains neutral with regard to jurisdictional claims in published maps and institutional affiliations.

Ready to submit your research? Choose BMC and benefit from:

- fast, convenient online submission

- thorough peer review by experienced researchers in your field

- rapid publication on acceptance

- support for research data, including large and complex data types

- gold Open Access which fosters wider collaboration and increased citations

- maximum visibility for your research: over $100 \mathrm{M}$ website views per year

At BMC, research is always in progress.

Learn more biomedcentral.com/submissions 